\title{
A Technique for Obtaining Uniform Inocula of Actinomyces israelii
}

\author{
By A. O. CHRISTIE* and J. W. POR'TEOUS \\ Department of Biological Chemistry, Marischal College, \\ University of Aberdeen, Scotland
}

(Received 24, March 1960)

\begin{abstract}
SUMMARY
The anaerobic filamentous organism Actinomyces israelii grows as discrete colonies which sediment in static liquid media and are too large and variable in size to be suitable for quantitative inoculations of experimental media. A stirredculture technique yielded uniformly small viable colonies of Actinomyces israelii. The microcolonies obtained still sedimented rapidly but could be kept in even suspension by bubbling nitrogen through the suspension. Such suspensions gave uniform inocula from a graduated Pasteur pipette as judged by total-nitrogen determinations and showed the growth characteristics of $\boldsymbol{A}$. israelii grown in static liquid media.
\end{abstract}

\section{INTRODUCTION}

In pure culture the anaerobic filamentous organism Actinomyces israelii grows in liquid media as discrete coherent colonies of 0.5-2.5 mm. diameter; the supernatant medium remains clear at all stages of growth. The colonies, variously described as 'cauliflower' or 'bread-crumb' in appearance (Erikson, 1940; Erikson \& Porteous, 1953), do not disperse on mild agitation of the culture vessel although the colonies of certain contaminated cultures will disintegrate (Erikson \& Porteous, 1955). The colonies of different pure strains in liquid culture vary in consistency, from those which can be fragmented into smaller colonies by the tip of a Pasteur pipette to those which are so tough as virtually to resist fragmentation by this means. As a preliminary to a quantitative study of the nutritional requirements of $A$. israelii some means of obtaining a uniform inoculum suspension of this organism was required.

Howell \& Pine (1956) studied thirteen strains of Actinomyces, five of which matched the partial description of Actinomyces israelii given above. These authors prepared their inocula by homogenizing a suspension of colonies in a tissue-grinder; the growth from such inocula was subsequently measured as the packed volume of harvested colonies, by determination of glucose utilization or, after repeatedly drawing and expelling the growing colonies through a sterile serological pipette at each time of measurement, by measuring the turbidity of the suspension. In the present work an attempt was made to repeat two of these homogenization techniques, but without success; colonies of all the strains used were too tough to submit to uniform fragmentation in an all-glass Potter \& Elvehjem homogenizer or to pass

* Present address : Marine Biology Station, Menai Bridge, North Wales. 
into a serological pipette with consequent dispersion. Attempts to modify the latter method by using a sterile syringe and needle were also unsuccessful. The homogenizer technique is open to the objection that contamination during treatment of the culture may occur; Erikson \& Porteous (1955) reported some of the difficulties consequent on slight contamination of $A$. israelii cultures. Attempts were also made to produce viable uniform suspensions of fragmented colonies by shaking with ballotini at $+\mathbf{2}^{\circ}$ in a vibrating disintegrator (Mickle, 1948) for different periods (5-300 sec.), with distilled water, $1 \%(\mathrm{w} / \mathrm{v}) \mathrm{NaCl}, 0.01 \mathrm{~m}-$ phosphate buffer ( $\mathrm{pH} 7)$ or the same buffer $+1 \%(\mathrm{w} / \mathrm{v})$ glucose, as suspending media. Shaking in the disintegrator for at least $\mathbf{3 0}$ sec. was required to produce an opalescent supernatant fluid, after allowing a further $2 \mathrm{~min}$. for large fragments to sediment. Inocula taken from such supernatant fluids into medium S of Erikson \& Porteous (1953) occasionally gave growth but no combination of the above conditions was found which consistently gave viable inocula of $\boldsymbol{A}$. israelii by this technique. Eventually the technique described below was worked out; this proved suitable for the preparation of uniform viable inocula of $A$. israelii, and has been used for the past two years.

\section{METHODS}

Organisms. Of twelve strains of Actinomyces israelii available, one (strain 'Wills') was selected as showing particular resistance to fragmentation by the techniques mentioned above. Cultures were maintained as described by Erikson \& Porteous (1953).

Culture media. In initial experiments, medium $\mathbf{S}$ and medium $\mathbf{A}$ of Erikson \& Porteous (1953) were used in the first and second stages of the technique to be described. Subsequently chemically defined media (Howell \& Pine, 1956) were used with equal success.

Sterilization. All apparatus was sterilized empty in the autoclave (15 lb./sq.in. for $\mathbf{3 0} \mathrm{min}$.) before addition of sterile medium.

Total-nitrogen determinations. Digestions were performed according to Chibnall, Rees \& Williams (1943); the distillations were carried out in the Markham (1942) apparatus, the ammonia trapped in boric acid and determined as described by Conway \& O'Malley (1942). Reagent blanks and standard $\left(\mathrm{NH}_{4}\right)_{2} \mathrm{SO}_{4}$ solutions were taken through the same procedure.

Apparatus. The stirred-culture apparatus used is shown in Fig. 1. The $500 \mathrm{ml}$. flasks contained magnetic stirrers and were plugged with cotton-wool and sterilized. The standard male joints, plugged with cotton-wool as indicated in Fig. 1, were separately sterilized with the tap-barrels removed. Sterile medium (100 ml.) added aseptically to each flask was inoculated from a stock culture of Actinomyces israelii by a Pasteur pipette. The cotton-wool plugs in the flasks were replaced aseptically by the sterile plugged male joints, each lightly smeared with sterile glycerol. Assembly of the apparatus was then completed with rubber-tubing joints as shown in Fig. 1 and the lubricated tap-barrels inserted. An indicator of anaerobiosis (Mackie \& McCartney, 1949) was placed in tube $T$. The complete apparatus was evacuated through $E$ at the water pump and filled with nitrogen three times.

Culture technique; first stage. The complete apparatus (Fig. 1) was incubated at $37^{\circ}$ without stirring for the first 2 days after inoculation. Each flask was then 
stirred with a magnetic stirrer at $60 \mathrm{rev} . / \mathrm{min}$. for a period of $4 \mathrm{hr}$. during each of the succeeding 3 days; the stirring broke up the growing colonies.

Culture technique; second stage. At the end of the first stage of culture lasting 5 days the fine suspension of microcolonies was allowed to sediment in the culture flasks before transferring approximately equal parts of the sediment with a Pasteur pipette to $50 \mathrm{ml}$. volumes of fresh medium in each of several $100 \mathrm{ml}$. conical flasks. Sufficient inoculum was added to cover the bottom of the flask with a thin layer of colonies. The medium in the flasks was sealed with sterile liquid paraffin and incubated, without stirring, for 4-5 days at $37^{\circ}$. The colonies were then aseptically harvested and washed with sterile distilled water three times by decantation.

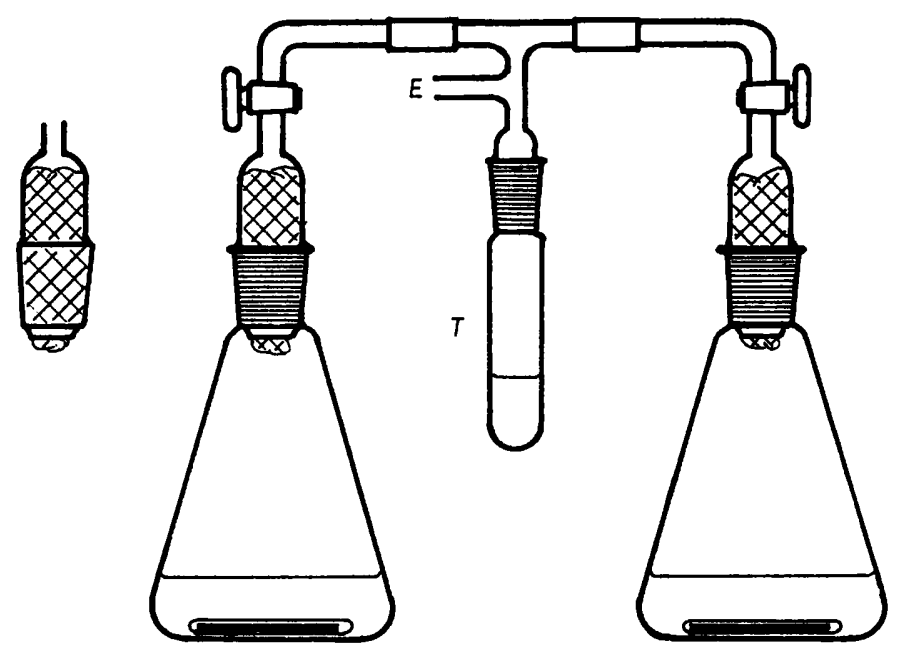

Fig. 1. The complete stirred-culture apparatus consisting of two $500 \mathrm{ml}$. conical flasks with standard female sockets; two plugged standard male cones fitted with stop-cocks; and a manifold connecting the flasks to a tube of anaerobic indicator and also providing an outlet $\boldsymbol{E}$ for filling the apparatus with nitrogen after evacuation.

Inoculation. The harvested and washed colonies were suspended in an equal volume of sterile distilled water in a test tube which was clamped at an angle of c. $20^{\circ}$ above horizontal, over a micro-burner. A slow stream of nitrogen, sterilized by passage through sterile cotton-wool, was bubbled through the suspension of microcolonies to keep them evenly dispersed. A sterile calibrated dropping pipette was used to transfer c. $50 \mu \mathrm{l}$. of the suspension of colonies to each $12 \times 75 \mathrm{~mm}$. culture tube containing $2 \mathrm{ml}$. of experimental medium. At several intervals during inoculation of culture media a $50 \mu \mathrm{l}$. volume of the microcolony suspension was transferred to a sterilized digestion tube containing $2 \mathrm{ml}$. sterile water. Digestion of the contents of these tubes then permitted determination of the total-nitrogen content of the inocula.

\section{RESULTS}

The colonies obtained in the final suspension by the above technique were remarkably uniform in size. They were still sufficiently large $(c .0 .2 \mathrm{~mm}$. diam.) to sediment rapidly but could be kept in uniform suspension by gassing. Table 1 shows that the 
technique described provided uniform inocula. Contamination during inoculation was not experienced; inoculation rates as high as 200 tubes/hr. were accomplished.

The filamentous morphology of Actinomyces israelii (Erikson, 1940) precluded assessment of the viability of the inocula of microcolonies by comparison of viable with total counts. The colonies in the inoculum suspension were, however, microscopically typical; they grew to normal size in a single subculture and, in not more than four serial subcultures in static media, reverted to their normal nodular shape. Provided inocula were taken from similar phases of growth, into identical media, stirred-culture inocula showed no increase in lag phase as compared with unstirredculture inocula of approximately the same size.

Table 1. The total-nitrogen content ( $\mu \mathrm{g} . \mathrm{N}$ ) of eight $50 \mu \mathrm{l}$. inocula of Actinomyces israelii obtained by the stirred-culture technique in three experiments

\begin{tabular}{|c|c|c|c|}
\hline \multirow[b]{3}{*}{ Inoculum } & \multicolumn{3}{|c|}{ Experiment } \\
\hline & (a) & $(b)$ & $(c)$ \\
\hline & \multicolumn{3}{|c|}{ Total nitrogen $(\mu \mathrm{g} . / 50 \mu \mathrm{l})}$. \\
\hline $\mathbf{1}$ & 21 & 17 & 20 \\
\hline 2 & 21 & 17 & $\mathbf{2 2}$ \\
\hline 3 & 20 & 19 & 20 \\
\hline 4 & 20 & 20 & 22 \\
\hline 5 & 22 & 19 & 23 \\
\hline 6 & 21 & 19 & 22 \\
\hline 7 & 20 & 18 & 21 \\
\hline 8 & 18 & 19 & 21 \\
\hline $\begin{array}{c}\text { Average } \\
\text { Range }\end{array}$ & $\begin{array}{c}20 \\
(18-22)\end{array}$ & $\begin{array}{c}19 \\
(17-20)\end{array}$ & $\begin{array}{c}21 \\
(20-23)\end{array}$ \\
\hline
\end{tabular}

\section{DISCUSSION}

The technique described, although undoubtedly tedious and time-consuming, has nevertheless yielded uniform inocula where other methods failed. The technique has the advantage that growth of the colonies takes place under conditions which prohibit entry of contaminants. The results suggest that the colonies produced by the technique were, apart from their size, identical with colonies grown in static media. The second-stage incubation was carried out for the following reasons: (i) it provided a useful indication of culture purity, the supernatant medium remaining characteristically clear and the colonies characteristically discrete; (ii) the smaller culture vessels facilitated harvesting of colonies; (iii) the amount of material available for experimental purposes was increased; (iv) it provided a period during which the microcolonies grew without becoming too large.

One of us (A.O.C.) was in receipt of a D.S.I.R. Research Studentship for the period October 1956 to October 1959.

\section{REFERENCES}

Chibnall, A. C., Rees, M. W. \& Williams, E. F. (1943). The total nitrogen content of egg albumin and other proteins. Biochem. J. 37, 354.

Conway, E. J. \& O'Malley, E. (1942). Microdiffusion methods. Ammonia and urea using buffered absorbents. (Revised methods for ranges greater than $10 \mu \mathrm{g}$. N.) Biochem. $J$. 36, 655 . 
ERIKson, D. (1940). Pathogenic anaerobic organisms of the Actinomyces group. Spec. Rep. Ser. med. Res. Coun., Lond., no. 240.

Erikson, D. \& Porteous, J. W. (1953). The cultivation of Actinomyces israelii in a progressively less complex medium. J. gen. Microbiol. 8, 464.

Erikson, D. \& Porteous, J. W. (1955). Commensalism in pathogenic anaerobic Actinomyces cultures. J. gen. Microbiol. 13, 261.

Howell, A. \& Pine, L. (1956). Studies on the growth of species of Actinomyces. J. Bact. 71, 47.

Mackie, T. J. \& McCantney, J. E. (1949). Handbook of Practical Bacteriology, 8th ed., p. 207. Edinburgh: E. and S. Livingstone.

MARKHAM, R. (1942). A steam distillation apparatus suitable for micro-Kjeldahl analysis. Biochem. J. 36, 790.

Mrckle, H. (1948). Tissue disintegrator. J. R. micr. Soc. 68, 10. 